$$
\begin{aligned}
& \text { PIITID/SNA--226 } \\
& \text { Technicel commen Cont } \\
& \text { NUCLEAR DIVISION }
\end{aligned}
$$

C002-EC090214-F1

ENGINEERING CRITICAL COMPONENT SPECIFICATION

\author{
PERFORMANCE/DESIGN AND \\ PRODUCT CONFIRMATION REQUIREMENTS \\ FOR \\ INSTRUMENTATION \& CONTROL SUBSYSTEM
}

FORMING A PART OF

CEI NUMBER 090290A
PRELIMINARY PROPOSAL ISSUE
DATED 12-15-69

FOR REVIEW ONLY. DO NOT IMPLEMENT.

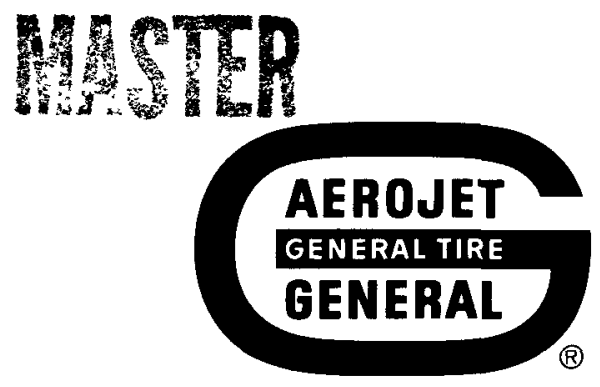

\title{
AEROJET-GENERAL CORPORATION
}

$$
\text { SACRAMENTO, CALIFORNIA }
$$

TECHNICAL DOCUMENT CENTER Nuclear Rocket Operations 


\section{DISCLAIMER}

This report was prepared as an account of work sponsored by an agency of the United States Government. Neither the United States Government nor any agency Thereof, nor any of their employees, makes any warranty, express or implied, or assumes any legal liability or responsibility for the accuracy, completeness, or usefulness of any information, apparatus, product, or process disclosed, or represents that its use would not infringe privately owned rights. Reference herein to any specific commercial product, process, or service by trade name, trademark, manufacturer, or otherwise does not necessarily constitute or imply its endorsement, recommendation, or favoring by the United States Government or any agency thereof. The views and opinions of authors expressed herein do not necessarily state or reflect those of the United States Government or any agency thereof. 


\section{DISCLAIMER}

Portions of this document may be illegible in electronic image products. Images are produced from the best available original document. 
Data Item Identification

No. C002-EC090214-F1
Engineering Critical

Component Specification No. EC-90214

Part I of Two Parts

Page -1 of 28

PERFGRMANCE/DESIGN AND QUALIFICATION REQUIREMENTS

for

INSTRUMENTATION \& CONTROL SUBSYSTEM

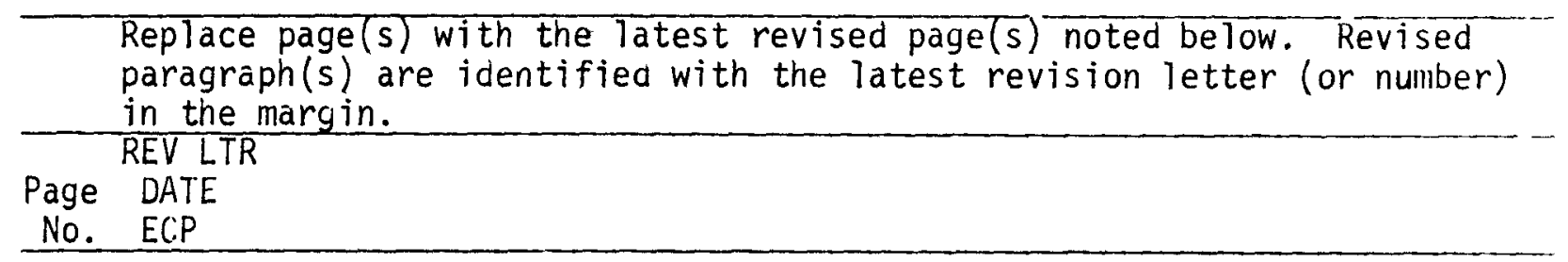

\section{NOTICE}

This report was prepared as an account of work sponsored by the United States Government. Neither the United States nor the United States Energy Research and Development Administration, nor any of their employees, nor any of their contractors, subcontractors, or their employees, makes any warranty, express or implied, or assumes any legal liability or responsibility for the accuracy, completeness or usefulness of any information, apparatus, product or process disclosed, or represents that its use would not infringe privately owned rights. 
1. SCOPE

This specification establishes the performance, design, test and qualification requirements for equipment identified as the Instrumentation and Controls Subsystem, hereinafter referred to as the I\&C Subsystem. The I\&C subsystem provides an aggregate of electromechanical and electrical/ electronic devices and assemblies to be used for sensing engine phenomena, signal transmissions, engine control, signal processing and electrical source conditioning and distribution.

\section{APPLICABLE DOCUMENTS}

2.1 Aerojet-General Corporation Documents. - The following documents, of the latest issue, form a part of this specification to the extent specified herein. In the event of conflict between documents referenced herein and other detailed content of Sections 3,4,5 and 10 the detailed requirements of Sections $3,4,5$ and 10 shall be considered a superseding requirements. SPECIFICATIONS

EC-90155 Electronic Power, Instrumentation and Control

EC-90177 Engine Instrumentation

EC-90179 Wiring Harness

EC-90216 Electrical Power Source

EC-* Nuclear Subsystem Instrumentation

CP-90290 Engine, NERVA, 75K, Full Flow

*To be supplied by WANL

DRAWINGS

1136874 Logic Diagram Malfunction Detection

1136875 NERVA I\&C Subsystem (Reference)

(Copies of above documents required by suppliers in connection with specific procurement functions should be obtained from the procuring activity) 
Specification No. EC-90214

\section{REQUIREMENTS}

3.1 Performance.- Except as otherwise specified herein, performance requirements for this equipment shall be in accordance with EC-90290 of which this equipment is a part.

\subsubsection{Functional Characteristics.-}

3.1.1.1 Performance Characteristics.- The I\&C subsystem shall reliably operate with the remainder of the nuclear rocket engine, the nuclear stage, and the complete mission vehicle; shall be capable of monitoring and controlling the engine throughout its range of operation; shall process and transmit data and command signals; and supply, convert, distribute and regulate power as required to perform these functions.

The I\&C subsystem shall provide the Nuclear and Engine sensors, signal processing, power, subsystem wiring, and instrumentation to meet the requirements for engine ground preparatory phases, boost phases, coast phases, engine startup, steady state operation, thrust vector control, throttling, shutdown, cooldown, engine safety, restart and disposal operations. The performance requirements to be met are as shown in Figure 1 and Table $I$. These performance requirements shall be met through five critical components of the I\&C subsystem.

(a) Electronic Power, Instrumentation and Control (EPIC)

(b) Wiring Harness (WH)

(c) Engine Instrumentation (EI)

(d) Electrical Power Source (EPS)

(E) Nuclear, Subsystem Instrumentation (NI) 
Specification No. EC-90214

3.1.1.1.1 Electronic Power, Instrumentation and Control (EPIC).- The EPIC shall be capable of startup operation, steady state operation, shutdown, cooldown, restart operation, thrust vector operation, and a disposal mode of operation. The electronics associated with these functions shall meet the requirements of engine controls and the engine measurement transmission system before, during, and after engine operation as required for ground checkout, and engine operation. The engine EPIC signal processing electronics shall convert engine signals into a form compatible with the nuclear stage and/or mission vehicle astrionics system(s) and/or crew command module monitoring system.

3.1.1.1.2 Wiring Harness.- The I\&C shall provide circuits for diagnostic and control electrical signals which are required by the I\&C subsystem and other NERVA engine subsystems as specified in drawing 1136875.

3.1.1.1.3 Engine and Nuclear Instrumentation.- The I\&C shall provide the Nuclear (WANL supplied) and engine instrumentation to sense engine parametric variables for purposes of engine control action, diagnostic and trend data retrieval.

3.1.1.1.4 Power Source Conditioning and Distribution.- The I\&C subsystem shall be capable of generating electrical power and regulating the power to the tolerances required by the various sensors, actuators, and EPIC. The electronics shall transmit the required signals and power within the I\&C and to the individual engine elements served that connect to the I\&C physical electrical interfaces for engine pretest, boost, coast, and operation phases.

3.1.1.1.5 Malfunction Detection.- The I\&C subsystem shall incorporate malfunction detection equipment and diagnostic instrumentation to detect incipient failures and provide for corrective action capability. The engine control system shall incorporate interlocks which will assure proper sequencing of a11 engine operations and that all operations are within allowable tolerances as specified in Table I and drawing 1136874. 
3.1.1.1.6 Safety Reporting.- The I\&C subsystem shall be capable of providing, to the stage and/or vehicle payload systems all electrical signals which warn of an incipient failure or improper engine operation.

3.1.1.1.7 Telemetry Input.- The I\&C subsystem shall provide, to the telemetry system, all signals necessary for ground evaluation of flight performance.

3.1.1.1.8 Failure Criteria.- The I\&C subsystem shall incorporate features that shall ensure that no single failure in the subsystem, within the reliability apportionment specified in 3.1 .2 .1 , shall preclude the achievement of mission objectives for the missions specified.

3.1.1.1.9 Sensor Redundancy.- The I\&C subsystem shall provide for redundancy of critical control and trend data sensors.

3.1.1.1.10 Manual Control.- The I\&C shall provide an override system. The override system shall permit the flight crew, or ground control working through telemetry links, to perform the override function.

3.1.1.1.11 Engine Control.- The I\&C electronics shall consist of elements that satisfy the relationships shown on Drawing 1136875. Control of engine binary and analog functions; locking mechanisms; servo loops; demand level changes; and other time or parametrically related events shall be exercised as required through the EPIC subsystem.

\subsubsection{Operability.-}

3.1.2.1 Reliability.- The reliability of the I\&C shall be a minimuml of 0.999014 such that the I\&C shall successfully meet all the performance requirements specified nerein. The other subsystem shall have reliability allocation as follows: 

(a) EPIC
0.999184
(b) WH
0.999996
(c) EI
0.999917
(d) NI
0.999917
(e) EPS
0.999999

3.1.2.2 Maintainability.- The I\&C subsystem shall be designed to incorporate maintainability features necessary to comply with the quantitative Mean Time To Repair (MTTR) and mean active maintenance time apportionments assigned in $\mathrm{CP}-90290$ and as follows:

(a) Mean Time to Repair (MTTR): The total I\&C subsystem apportionment for launch and flight significant performance of corrective maintenance tasks that contribute to system downtime shall be four hours.
(1) EPIC 4 nours
(3) NI
$<$ nours
(b) EPS 4 hours
(2) WH 4 hours
(4) EI 2 hours

(b) Mean Active Maintenance Time: The I\&C subsystem apportionment for mean active maintenance time shall be as follows:
(1) EPIC
0.5 manhours
(2) WH
0.2 manhours
(3) NI
0.1 manhours
(4) EI
0.1 manhours
(5) EPS
0.5 manhours

(c) Maintainability Design: The I\&C subsystem shall be designed to meet the following maintainability objectives:

(1) Selected equipment components shall be accessible for circuit tests, adjustments, unscheduled maintenance and repair.

(2) Component mounting shall be such that removal and replacement can be effected easily, when no hazard exists to maintenance personnel and without sacrificing the basic integrity of the system. 
(3) I\&C subsystem components shall be interchangeable and standardized consistent with the design requirements to ensure minimum spares loading and maximum return from system down status to operational readiness.

(4) The requirement for the use of special tools for maintenance shall be held to a minimum.

(5) Necessary maintenance shall be accomplished with minimum disturbance to interfacing equipment.

(6) Required maintenance shall be performed by qualified technicians.

(7) Components shall be designed to afford a minimum of maintenance and recalibration.

3.1.2.2.1 Maintenance and Repair Cycles.- The I\&C subsystem shall not require scheduled maintenance under the storage conditions specified in 3.1.2.3 and 3.3.11. The I\&C design sha11 incorporate features for performance of unscheduled maintenance activities.

3.1.2.2.2 Service and Access.- The I\&C subsystem shall be designed and constructed for ease of servicing and access as follows:

3.1.2.2.2.1 Remote Maintenance.- Remote maintenance shall be in accordance with requirements specified in CP-90290.

\subsection{Circuit Access.- The I\&C subsystem shall be designed to} provide circuit access to the signal processing equipment upon receipt of suitable signals from the vehicle system for preflight checkout and prior to each engine operation. 
Specification No. EC-90214

3.1.2.2.2.3 Checkout.- The I\&C subsystem shall incorporate circuitry to meet the following checkout functions:

(a) Functional Checks: The I\&C shall be capable of accepting externally generated signals from the vehicle system for engine functional checkout. All engine mounted control components shall be accessible through I\&C circuitry. The engine functional check capability shall be effective for prelaunch, boost and flight mission phases.

(b) Self Check: The I\&C subsystem shall incorporate means for vehicle system initiated signal access to the EPIC self-check functions for purposes of engine pre-operational checkout. The I\&C self-check function shall validate all I\&C circuit elements prior to launch vehicle mission operations.

3.1.2.2.2.4 Self Repair.- The I\&C subsystem shall include the capacity for functional self repair of operating controls through functional substitution in such a manner that critical components shall be maintained, replaced or substituted for, before, during, and after engine operation.

3.1.2.2.2.5 Manual Maintenance.- The I\&C subsystem shall be designed and constructed so that effective maintenance can be performed.

(a) Modular Construction: The I\&C subsystem shall be designated in accordance with a replaceable modular concept.

(b) In-Use Maintenance: The I\&C subsystem design shall include features to allow rapid replacement of operational modules consistent with the maintainability goals specified in 3.1.2.2.

3.1.2.3 Useful Life.- The I\&C shall have a minimum useful life of 9 years as follows: 
(a) Rated operating life

(b) Non-rated operating life (transients checkout)

(c) Space Storage (including (a) and (b))

(d) Ground

(1) Storage (see 3.3.11)

(2) Final assembly to launch pad (1ess storage)

(3) Launch pad environment standby time
600 minutes

(max. of 60 cycles)

72 days

3 years

5 years

6 months

6 months

\subsubsection{Environmental. -}

3.1.2.4.1 Natural Environment.- The natural environment experienced by the I\&C shall be as specified in CP-90290.

3.1.2.4.2 Induced Environments.- The I\&C shall be subjected to the following induced environments:

(a) Vibration
(1) Longitudinal
$+6.75 \mathrm{~g}(3$ to $35 \mathrm{~Hz})$
(2) Lateral
$+4.5 \mathrm{~g}(0.1$ to $15 \mathrm{~Hz})$

(b) Acceleration
(1) Longitudinal
+5.2 to $-1.0 \mathrm{~g}$
(2) Lateral
$\pm 1.09$

(c) Shock: The I\&C shall be designed to operate and perform satisfactorily after exposure to various shock events. These shocks shall be considered as not combining with vibration or acceleration environment. Shock responses up to $300 \mathrm{~Hz}$ shall be considered unidirectional acting along the longitudinal axis of the stage. High frequency response above $300 \mathrm{~Hz}$ will be 
Specification No. EC-90214

considered to be predominately undirectional. The I\&C major components, except for cable hardness to which Tungsten/Rhenium probes are attached shall withstand, without degradation of operational capability, flush drops of up to one inch and pivot drops of up to four inches from all possible orientations onto a nard concrete surface in the unpackaged condition.

(b) Acoustic Noise: The acoustic noise spectrum as specified in EC-90290, shall be consiaered as minimum I\&C design requirements based upon environments experienced during lift-off and through the maneuver of maximum dynamic pressure $(\max q)$.

(e) Nuclear Radiation: The equipment shall be designed to exhibit satisfactory performance after exposure to nuclear reactor radiation. Nuclear radiation envirunment shall be considered to combine with temperature and low pressure conditions. These requirements are:

(1) The predicted nuclear environment is highly dependent on the location of the I\&C equipment. If the component is located at tank top the total mission doses and maximum radiation rates from the nuclear rocket engine are:

(1) Neutrons

0

(2) Gammas

$$
\begin{array}{ll}
\text { Tctal Dose } & 1400 \text { Rads } \\
\text { Maximum Dose Rate } & 140 \text { Rads/hr }
\end{array}
$$

(2) If the component is located below the propellant tank and above the disk shield the maximum radiation rates and doses for full power operation are:

(1) Neutrons
Integrated Fluence
$7.2 \times 10^{16} \mathrm{n} / \mathrm{cm}^{2}$ (E I Mev)
Maximum Flux Rate
$2.1 \times 10^{12} \mathrm{n} / \mathrm{cm}^{2}-\sec (\mathrm{t} \cdot 1 \mathrm{Mev})$ 
Specification No. EC-90214

(2) Gammas
Total Dose
$4.3 \times 10^{8}$ Rads
Maximum Dose Rate
$4.3 \times 10^{7}$ Rads $/ \mathrm{hr}$

(3) If the component is located between the disk shield and pressure vessel dome, the maximum radiation rates and doses for full power are:

(1) Neutrons

$$
\begin{array}{ll}
\text { Integrated Fluence } & 7.2 \times 10^{18} \mathrm{n} / \mathrm{cm}^{2}(\mathrm{t} \cdot 1 \mathrm{Mev}) \\
\text { Maximum Flux Rate } & 2.0 \times 10^{14} \mathrm{n} / \mathrm{cm}^{2}-\mathrm{sec}(\mathrm{t} 1 \mathrm{Mev})
\end{array}
$$

(2) Gammas
Total Dose
$1.3 \times 10^{8}$ Rads
Maximum Dose Rate
$1.3 \times 10^{7}$ Rads/hr.

(4) If the component is located on the engine below the pressure vessel dome, the maximum radiation rates and doses for full power are:

(1) Neutrons

Integrated Fluence

$8.6 \times 10^{18} \mathrm{n} / \mathrm{cm}^{2}$ ( $\left.\mathrm{E} \cdot 1 \mathrm{Mev}\right)$

Maximum Flux Rate

$2.4 \times 10^{14} \mathrm{n} / \mathrm{cm}^{2}-\mathrm{sec}(\mathrm{E} \quad 1 \mathrm{Mev})$

(2) Gammas

Total Dose

$3.5 \times 10^{10}$ Rads

Maximum Dose Rate

$3.5 \times 10^{9}$ Rads $/ \mathrm{hr}$ 
(f) Temperature: The following operating and non-operating temperature shall apply. Where necessary, transportation and storage facilities, stage environmental protection or stage designs shall ensure that temperature extremes are not exceeded.

(1) Transportation (Non-Operating): Low of $420^{\circ} \mathrm{R}$ or a high of $+160^{\circ} \mathrm{F}$ for four hours out of any 24-hour period.

(2) Storage (Non-Operating): $475^{\circ}$ to $600^{\circ} \mathrm{R}$

(3) Prelaunch and Flight:

a Items mounted on thermally conditioned panel $460^{\circ} \mathrm{R}$ with item in a one atmosphere ambient. $600^{\circ} \mathrm{R}$ with item in ambient of $10^{-10} \mathrm{~mm} \mathrm{Hg}$.

The foregoing temperature extremes shall be considered as that of the circulating fluid at the inlet to the thermally conditioned mounting panel and surrounding surfaces.

b Items mounted on structure other than conditioned panels -

$37^{\circ} \mathrm{R}$ with item in an ambient of $10^{-10} \mathrm{~mm} / \mathrm{Hg}$. $540^{\circ} \mathrm{R}$ with item in a one atmosphere ambient. $2600^{\circ} \mathrm{R}$ with item in an ambient of $10^{-10} \mathrm{~mm} / \mathrm{Hg}$.

The above temperature extremes shall be considered as that of the surrounding surfaces. 
(g) Pressure: The following operating and non-operating pressure conditions shall apply:

(1) Transport and Storage: 15.4 to 3.4 psia

$$
\Delta P \text { in } \mathrm{psi} / \mathrm{min}-1.25
$$

(2) Powered Flight: $10^{-6} \mathrm{~mm} / \mathrm{hg}$ combined with temperature and nuclear radiation environments in earth orbit and $10^{-10} \mathrm{~mm} / \mathrm{Hg}$ for transsolar system trajectories.

(h) Explosive Atmosphere: The I\&C shall be designed to operate within an explosive atmosphere of air and gaseous hydrogen. Operation shall not cause ignition or explosion of the $\mathrm{H}_{2}$ /air mixture. The I\&C sha11 be capable of operating in an inert atmosphere during launch preparatory and boost phase.

(i) Charged Particles: The I\&C shall be designed to withstand the following flux levels

(1) Electron Flux - Peak Intensity:

$$
\begin{aligned}
& >20 \mathrm{Kev}-2 \times 10^{10} \text { Particle } / \mathrm{cm}^{2} \mathrm{sec} . \\
& >200 \mathrm{Kev}-1 \times 10^{8} \mathrm{Particle} / \mathrm{cm}^{2} \mathrm{sec} . \\
& >600 \mathrm{Kev}-1 \times 10^{7} \text { Particle } / \mathrm{cm}^{2} \mathrm{sec} .
\end{aligned}
$$

(2) Proton Flux - Peak Intensity:

$$
\begin{aligned}
& >10 \mathrm{Mev}-10^{7} \text { Particle } / \mathrm{Cm}^{2} \mathrm{sec} . \\
& >40 \mathrm{Mev}-2 \times 10^{4} \text { Particle } / \mathrm{Cm}^{2} \mathrm{sec}
\end{aligned}
$$


Specification No. EC-90214

(j) Electromagnetic Radiations:

(1) Ultraviolet Light and X-Rays: Vehicle structure shall provide adequate protection to the I\&C from solar radiations.

(2) Gammas: Solar flares accompanied by intense geomagnetic storms indicate intense pulses of gammas are released into space. The I\&C may be subjected to bursts of radio noise as a function of these pulses. Suitable shielding shall be incorporated to el iminate the effect of these bursts of radio noise.

3.1.2.5 Transportability.- Loads experienced by the I\&C during transport phases shall not result in controlling design loads. Components of the I\&C that are fabricated and/or procured at various geographic locations shall incorporate provision to be transported by standard transportation means to a final assembly location. After checkout and acceptance tests, the assembled I\&C shall be transportable in accordance with CP-90290.

\subsubsection{Human Performance.- The I\&C design shall incorporate features} that minimize the possibility of human error during operation; minimize operation and maintenance personnel skill and training requirements; and provide operator signal interface(s) required for engine system man rating.

3.1.2.7 Safety.- The I\&C design shall incorporate features that conform to the requirements specified in CP-90290.

\subsection{Flight Safety.-}

3.1.2.7.1.1 Engine Shutdown.- In the event that malfunction protection, redundancy, and crew action cannot prevent loss of engine operation, the I\&C shall provide for safe transition from operating conditions to a shutdown condition upon receipt of a stage/vehicle/payload shutdown signal. 
Specification No. EC-40214

\subsection{1 Shutdown Criteria.- Shutdown shal1 be initiated by} stage/vehicle/payload system upon receipt of signals from suitable I\&C detection circuits. The action of the shutdown shall reduce the engine operating level such that subcritical operation is achieved. Circuits shall be provided for crew/guidance to bypass the detection circuits.

\subsection{2 Vehicle Emergency Detection System Shutdown.- Engine} shutdown shall be initiated by I\&C circuitry upon receipt of a shutdown signal from the vehicle emergency detection system.

3.1.2.7.1.2 Failure.- The I\&C shall incorporate circuitry to transmit appropriate signals to the vehicle emergency detection system if engine system malfunction protection, redundancy, crew action, and/or shutdown action fails to correct an engine system anomaly. The signals shall reflect that a degraded engine condition exists and that control cannot be effectively exercised any longer.

3.1.2.7.2 Ground Safety.- The I\&C shall include the capability to preclude the inadvertent operation of engine subassembly components during prelaunch preparatory phases.

3.1.2.7.3 Nuclear Safety.- The I\&C shall incorporate circuitry to comply with the nuclear safety requirements specified in CP-90290.

3.1.2.7.4 Personnel Safety.- The I\&C shall include circuitry designs that provide for maximum safety to personnel that are performing maintenance operations. Open power busses shall be clearly marked with caution notices. Circuits that exhibit precise adjustment requirements that in turn affect mission success shall be identified clearly as potential safety significant functions. 
3.1.2.7.5 Explosive and/or Ordnance Safety.- The I\&C shall include circuits and provisions for engine ordnance explosive and/or ordnance safety oriented functions.

\subsection{CEI Definition.-}

3.2.1 Interface Requirements.- The functional, physical, electrical, and environment interfaces between the I\&C and other equipment and facilities shall be as defined in the following paragraphs.

3.2.1.1 Schematic Arrangement.- The schematic arrangement of the interfaces which the I\&C has with other system equipment shall be as shown on Drawing 1136875.

3.2.1.2 Detailed Interface Definition.- The interface relationship of the I\&C shall be in accordance with the following subparagraphs.

3.2.1.2.1 Mechanical Interface.- The mechanical interface of the I\&C shal1 be in accordance with Drawing 1136875.

3.2.1.2.2 Functional Interface.- The functional interface of the I\&C shal1 be in accordance with Drawing 1136875.

3.2.1.2.3 Engine Control Component Interfaces.- The I\&C electronics shall interface with the following system components for control of the engine: 
Specification No. EC-90214

$\begin{array}{rll}\text { Quanity } & \text { Component } & \text { Operation } \\ 2 & \text { PSOV } & \text { Binary } \\ 2 & \text { PDKV } & \text { Binary } \\ 2 & \text { SSCV } & \text { 2-Way Valves - Electrical Analog } \\ 2 & \text { SSBV } & \text { Binary Valves, Operationally have } \\ 2 & \text { SSBV } & \text { different function } \\ 2 & \text { TBV } & \text { Binary } \\ 2 & \text { CSCV } & \text { Analog Cooldown System } \\ 18 & \text { Drums } & \text { Analog } \\ 2 & \text { Thrust Vector } & \text { Analog (1 Pitch, 1 Yaw) } \\ 100 & \text { Actuator } & \text { Binary } \\ 7 & \text { Engine Destruct } & \\ 2 & \text { Package Squibs } & \text { Binary } \\ 1 & \text { Purge Valves } & \text { Bnalog } \\ 2 & \text { CSKV } & \text { Binary }\end{array}$

\subsubsection{Component Identification.-}

3.2.2.1 Government Furnished Property List.- The I\&C shall incorporate no government furnished equipment or materials.

3.2.2.2 Engineering Critical Components List.- The I\&C incorporates the following engineering critical components:

$\begin{array}{ll}\text { EC-90155 } & \text { Electronic Power, Instrumentation and Control } \\ \text { EC-90177 } & \text { Engine Instrumentation } \\ \text { EC-90179 } & \text { Wiring Harness } \\ \text { EC-90216 } & \text { Electrical Power Source } \\ \text { EC-* } & \text { Nuclear Subsystem Instrumentation }\end{array}$

*To be supplied by WANL 
Specification No. EC-90214

\subsubsection{Logistics Critical Components List.- The I\&C shall incorporate} no logistic critical components.

\subsection{Design and Construction.-}

3.3.1 General Design Features.- The I\&C shall be designed and constructed to be compatible with the foregoing specifications and the flight module structure and electrical configuration. Additional design features shall be in accordance with the following.

3.3.1.1 Drawing and Data.- The I\&C shall be described by Drawing 1136875.

3.3.1.2 Mechanical Criteria.- The I\&C shall be designed insofar as practicable to incorporate modular features. The mechanical design shall provide features for low thermal resistance paths to the package mounting structure and for high nuclear radiation resistance. The I\&C target maximum weight shal1 be 1970 pounds. The weight of the parts are:

$\begin{array}{ll}\text { EPIC } & 600 \text { pounds } \\ \text { WH } & 660 \text { pounds } \\ \text { EI } & 200 \text { pounds } \\ \text { NI } & 100 \text { pounds } \\ \text { EPS } & 410 \text { pounds }\end{array}$

The mechanical design shall satisfy all functional requirements specified for envelope, physical mounting, weight, cable interfaces, the operational environment and maintenance access.

3.3.1.3 Electrical Criteria.- The I\&C electrical design shall comply with the applicable requirements specified in CP-90290 and as follows: 
3.3.1.3.1 Electrical Signals. - The I\&C shall provide circuits that are consistent with signal transmission requirements.

3.3.1.3.2 Shielding.- The I\&C shall incorporate suitable circuit shielding to minimize the possibility of extraneous or spurious noise interference induction that is capable of causing engine operation outside of design 1 imits.

3.3.1.3.3 Circuit Access.- The I\&C design shall provide circuit access such that all engine mounted control and monitoring components shall be operated and/or monitored by crew/guidance upon receipt of the appropriate command signal.

3.3.1.3.4 Redundancy.- The I\&C subsystem design shall incorporate component and circuit redundancy and other techniques as necessary to meet the reliability requirements specified in 3.1 .2 .1 .

3.3.1.3.5 Spare Circuits.- The I\&C shall incorporate provisions for spare circuits.

3.3.1.3.6 Connectors.- The I\&C design shall provide means for rapid disconnection/connection from module cable termination.

3.3.1.3.7 Adjustment and Test. - The I\&C design shall incorporate means for minor circuit adjustments where required and for test equipment access.

3.3.1.4 Nuclear Design.- The I\&C shall be designed to withstand the nuclear radiation environment specified in 3.1.2.4 without degradation of performance as specified herein.

3.3.1.5 Installation. - The I\&C elements shall be designed to be capable of being installed on the nuclear stage and engine subassembly during the various phases of system assembly operations. 
Specification No. EC-90214

3.3.1.6 EPIC.- The EPIC shall be designed to receive power from the EPS and process all electrical functions to and from the engine and to the telemetry system or crew area. Processing includes all functions necessary to the control, analysis, and safety of the engine and crew.

3.3.1.7 Wiring Harness.- The wiring harness shall be designed to provide the "electrical link" between the engine and the engine/tank interface. All electrical functions on the engine shall be carried through the wiring harness which shall be capable of being disconnected at the engine/tank interface. The wire harness shall have three primary functions.

(a) Engine Instrumentation - Non-Integral: The wiring harness shall consist of those instruments which are not an integral part of another component, i.e., a potentiometer or an actuator, the connective cable, and the engine portion of the electrical engine/tank connector.

(b) Engine Instrumentation - Integral: The wiring harness shall consist of the attaching device, connecting cable, and engine portion of the engine/tank electrical connector for all non-nuclear electrical devices which are an integral part of another component.

(c) Nuclear Instrumentation: The wiring harness shall consist of the connecting device(s), connecting cable and engine portion of the engine/ tank electrical connectors. The harness shall provide connection to all electrical components on the nuclear subsystem and be compatible with radiation and other environments as specified in CP-90290.

3.3.1.8 Engine Instrumentation.- The engine instrumentation shall be designed to provide the measurement data necessary to evaluate system performance, to detect unsafe operating conditions, to detect incipient failure, and to provide the necessary feedback information to operate the control system when used in conjunction with the nuclear instrumentation and 
instruments installed as an integral part of other components. The engine instrumentation shall consist of the sensors, other than those integrated in other components, any mounting hardware, and adequate cable to interface with the wiring harness and thermocouple reference functions.

3.3.1.9 Nuclear Instrumentation.- The nuclear instrumentation shall consist of the internally mounted sensors (internal to the pressure vessel) and cable, which shall exit from the pressure vessel for interfacing. In addition to the internal sensors, sensors shall be incorporated in the nonreactor components, i.e., control drum actuators. Interface requirements shall be in accordance with CP-90290.

3.3.1.10 Electrical Power Source.- The electrical power source shall provide the primary electrical power required to operate the engine. This electrical power supply shall be used to operate the engine actuators, engine valves, EPIC, and provide thrust vector control. The power delivered by the power source shall be in a form which is directly usable by the components.

\subsubsection{Selection of Specifications and Standards. - The selection of} specifications and standards shall be as specified in CP-90290.

3.3.3 Matertals, Parts and Processes.- The selection and application of materlals, parts and processes shall be as specified in CP-90290.

3.3.4 Standard and Commercial Parts.- The use and control of standard and commercial parts shall be as specified in CP-90290.

3.3.5 Moisture and Fungus Resistance. - Control of moisture and fungus resistance shall be as specified in CP-90290.

3.3.6 Corrosion and Metal Parts.- Corrosion of metal parts shall be controlled as specifled in CP-90290. 
3.3.7 Interchangeability and Replaceability.- The criteria for interchangeability and replaceability shall conform to the requirements specified in CP-90290.

3.3.8 Workmanship.- Workmanship shall conform to the requirements specified in CP-90290.

3.3.9 Electromagnetic Interference.- Compatibility of electromagnetic interference shall conform to the requirements specified in CP-90290.

3.3.10 Identification and Marking.- Identification and marking shall conform to the requirements specified in CP-90290.

3.3.11 Storage.- The I\&C shall be capable of performing as specified herein subsequent to storage while protected from the ground environmental conditions specified in 3.1.2.4 for a period not exceeding the ground storage life specified in 3.1 .2 .3 


\section{Table I}

\section{PERFORMANCE REQUIREMENTS}

1. START-UP

a. 60 Starts

b. Maximum start-up time (from start signal to initiation of bootstrap) - 23 seconds

c. Chilldown time shal1 not exceed 23 seconds (from initiation of propellant flow until engine is conditioned for bootstrap).

d. Start-up time predictability shall be \pm 10 seconds of the actual time required before the programming function shall commence.

e. Secondary requirements

Start-up to be accomplished with following variation in reactivity contribution:

$\begin{array}{lr}\text { Corrosion loss } & \$ 3.00 \\ \text { Zenon poisoning } & 0.35 \\ \text { Core and reflector } & 1.00 \\ \text { Thermal Effects } & 0.85\end{array}$

Changes in material temperature shall be 1 imited to rates not greater than $750^{\circ} \mathrm{R} / \mathrm{sec}$

Flow insertion reactivity during bootstrap shall not cause a period scram. 
Table I (cont.)

Pressure overshoot on bootstrap shall not exceed 20 psia.

Start-up shall not trip pump or turbine overspeed limits.

Override controllers shall be in fast follow-up mode during start-up if their motion during this time would likely activate the override.

2. RAMP TO OPERATING POINT

10 Minute Operation at Rated Conditions High Isp Start-up $150^{\circ} \mathrm{R} / \mathrm{Sec}$ Nominal at start of bootstrap point $\left(\frac{+300^{\circ} \mathrm{R}}{-340^{\circ} \mathrm{R}}\right)$

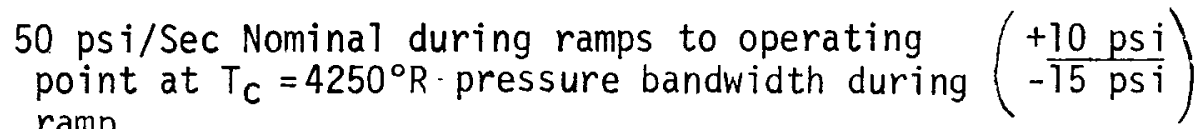
ramp.

Secondary Requirements
a. Isp
$816 \pm 0.75 \% \mathrm{sec}$
b. Thrust $75,000 \pm 2000 \mathrm{lb}$
c. PC 450 psia \pm 4 psia
d. Tc $4250^{\circ} \mathrm{R} \pm 10^{\circ} \mathrm{R}$

3. THROTTLING

\author{
Constant Temperature \\ $60 \%$ of Nominal Thrust \\ Pc \\ Ramp Rate
}

$\pm 50^{\circ} \mathrm{R}$

45,000 lb nominal

270 psia

$50 \mathrm{psi} / \mathrm{sec}$ nominal

4. TEMPERATURE RETREAT

$150^{\circ} \mathrm{R} / \mathrm{Sec}$ Nominal $\pm 100^{\circ} \mathrm{R}$ at Start of retreat 
Table I (cont.)

\section{PUMP TAILOFF}

Predictable Impulse and Time $\pm 15,000 \mathrm{lb} \mathrm{sec}$ and $\pm 5 \mathrm{sec}$

Secondary Requirements:

$1_{\text {sp }}$ shall be maximum during shutdown consistent with the temperature and pressure profile shown in Figure 1.

6. COOLDOWN

Reactor Temperature Limits

Engine Temperature Limits

Predictability at Isp and Time

Impulse Control $1692^{\circ} / 1592^{\circ} \mathrm{R}$

$1692^{\circ} / 1592^{\circ} \mathrm{R}$

$\pm 15,000 \mathrm{lb} / \mathrm{sec}$

$+10 \mathrm{sec}$

30,000 1b Nominal

$516.6 \mathrm{sec}$ Nominal

211.0 psia Nomina 1

$2248^{\circ} \mathrm{K}$ Nomina 1

8. SHUTDUWN/COOLDOWN

$$
\begin{aligned}
& \text { Within } \pm 20,000 \mathrm{lb} / \mathrm{sec} \\
& \text { Within } \pm 15 \mathrm{sec} \text { repeatibility }
\end{aligned}
$$

9. GIMBAL ASSEMBLY SUBSYSTEM

$\pm 3^{\circ}$ position minimum

$\pm 4^{\circ}$ position maximum

$0.75 \%$ sec minimum

$0.5^{\circ} / \mathrm{sec}^{2}$ minimum, $0.75^{\circ} / \mathrm{sec}^{2}$ maximum 


\section{Table I (cont.)}

10. DESTRUCT SUBSYSTEM

Explosive charge detonation during the boost to orbit phase of operation.

11. MALFUNCTION DETECTION

A. Categories
a. Shutdown
b. Emergency Mode
c. Special Action
d. Normal Controls
e. No action

B. Components

PSOV

TBV

BCV

SSCV

SSBV

SSBV

CSCV

Drums (a11)

Drums (single)

TPA

C. Malfunction Detection System

Normal Controls

$\frac{D P}{D T}$ 


\section{Table I (cont.)}

BCV Override

Drum Override

SSCV Override

Overspeed

Valve Failure System

Vibration of Pump 


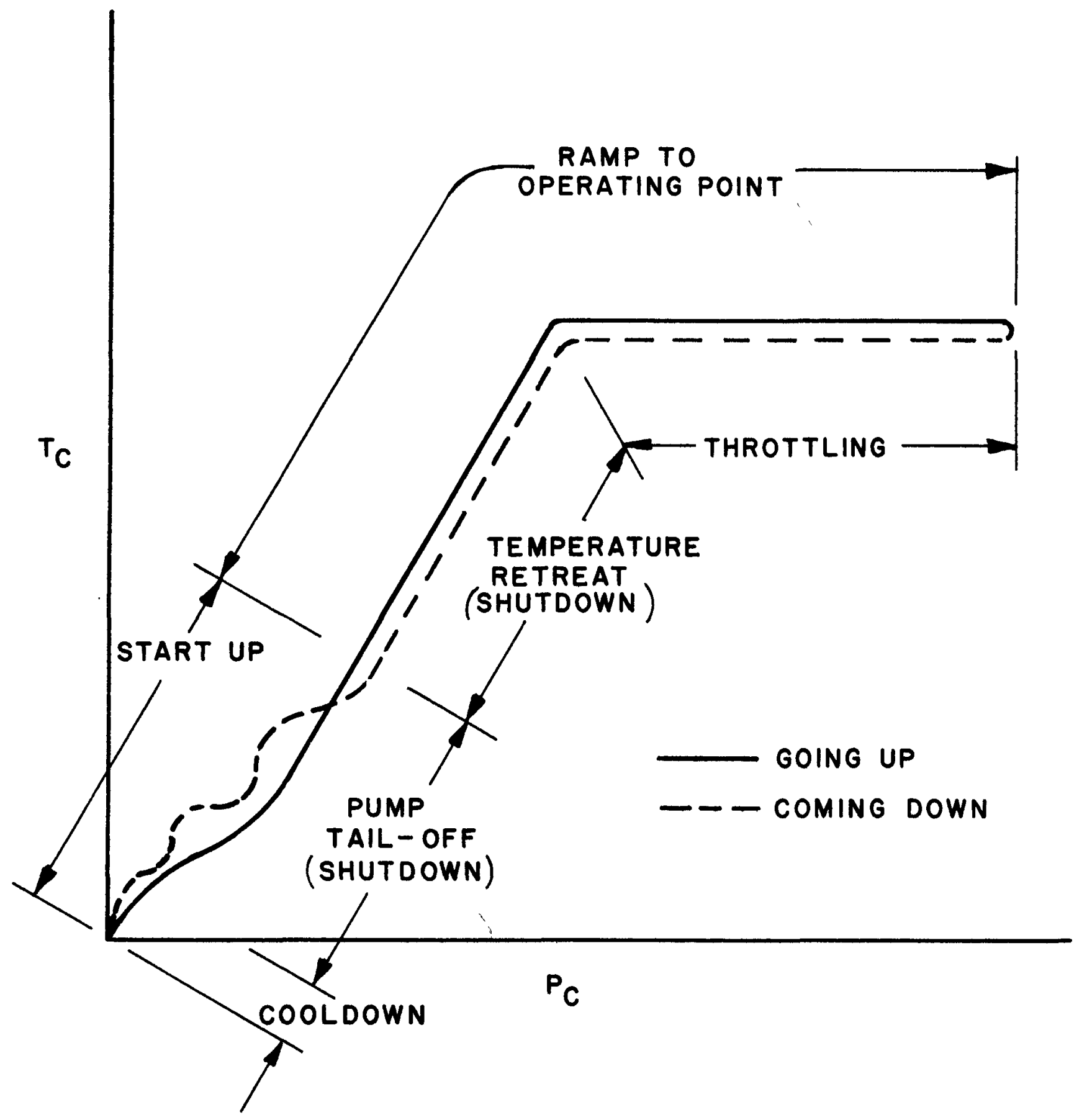

FIG. I PERFORMANCE REQUIREMENTS 